\title{
Original article \\ Comparison of 550 cases of surgical and natural menopause in respect to Genito-urinary Syndrome of Menopause (GSM)
}

Nusrat Mahjabeen, Sk. Zinnat Ara Nasreen.

\begin{abstract}
:
Natural menopause and surgical menopause are used interchangeably when conditions of patients are discussed. But they are different entirely. One is a natural stage of life that all women experience, the other is the result of surgery. This prospective observational study was conducted in the Department of Obstetrics and Gynaecology, Z.H. Sikder Women's Medical College \& Hospital, Dhaka from January 2016 to December 2018 over a period of three years to compare the GSM effects in natural and surgical menopause cases. During the study period a total of 275 patients with surgical menopause and 275 patients with natural menopause were enrolled employing purposive sampling method using a predesigned data collection sheet. Age of the most of the patients in surgical menopause group was within 41 to 50 years and most of the patients were $>50$ years old in natural menopause group. Most of the patients were illiterate in both groups and maximum patients were poor in both groups. Hot flush $(48.0 \%$ vs $28.0 \%)$, dryness of vagina $(12.0 \%$ vs $0.0 \%)$ and dyspareunia $(72.0 \%$ vs $28.0 \%)$ were found significantly higher in surgical menopause than natural menopause. Dysuria $(92.0 \%$ vs $40.0 \%)$ and increased frequency of urination $(68.0 \%$ vs $36.0 \%)$ were significantly higher in surgical menopause than natural menopause group. Urgency, hesitancy and incontinence of urination were significantly lower $(\mathrm{p}=<0.001)$ in surgical menopause than natural menopause group. In most of the surgical menopause cases, ovaries were also sacrificed. And this may be the reason of more deleterious effects in surgical menopause than natural menopause. So, it is highly recommended to preserve ovaries in hysterectomies due to benign indications.
\end{abstract}

\section{Keywords: GSM, surgical menopause and natural menopause.}

\section{Introduction:}

Menopause is the permanent cessation of menstruation resulting from reduced ovarian hormone secretion that occurs either naturally or is induced by surgery, chemotherapy, or radiation. Natural menopause can be recognized after 12 months of amenorrhea that is not associated with a pathologic cause. ${ }^{1}$ Surgical menopause is the cessation of menses resulting from surgical removal of the uterus, leaving one or both ovaries, or the removal of both ovaries. ${ }^{2}$

The genitourinary syndrome of menopause (GSM) is a new term that describes various menopausal symptoms and signs associated with physical changes of the vulva, vagina, and lower urinary tract. The GSM includes not only genital symptoms (dryness, burning, and irritation) and sexual symptoms (lack of lubrication, discomfort or pain, and impaired function), but also urinary symptoms (urgency, dysuria and recurrent urinary tract infections). ${ }^{3}$

The syndrome or its features manifest in some manner in approximately $15 \%$ of premenopausal women ${ }^{4}$ and $40-54 \%$ of postmenopausal women. ${ }^{5}$ Because women have a higher life expectancy than men, and $>17 \%$ of the population will be age $>65$ years by 2030 , the consequences of declined endogenous estrogen levels in menopausal women should be of great interest to clinicians. ${ }^{6}$

In Western women, $45 \%$ to $63 \%$ of postmenopausal women reported that they had experienced vulvovaginal symptoms, ${ }^{7}$ most commonly vaginal dryness; other symptoms included dyspareunia, vaginal irritation, itching sensation, vaginal tenderness, and vaginal bleeding or spotting during intercourse. ${ }^{7-9}$ Similarly, in a Korean study, $49 \%$ of postmenopausal women had experienced vulvovaginal symptoms including vaginal dryness and dyspareunia. ${ }^{10}$

As a result of estrogen deficiency after menopause, anatomic and histologic changes occur in female genital tissues, including reduction in the content of collagen and hyaluronic acid and in the levels of elastin, thinning of the epithelium, alterations in the function of smooth muscle cells, increase in the density of connective tissue, and fewer blood vessels. These changes reduce elasticity of the vagina, increase vaginal $\mathrm{pH}$, lead to changes in vaginal flora, diminish lubrication, and increase vulnerability to physical irritation and trauma. ${ }^{11,12}$

The female genital tract and lower urinary tract share

\section{Address of correspondence:}

Nusrat Mahjabeen, Assistant Professor, Department of Obs. \& Gynae, Z H Sikder Women's Medical College \& Hospital, Dhaka.Cell: 01626771927; Email: nusrat.bonny63@gmail.com 
a common embryonic origin, both arising from the urogenital sinus. As estrogen plays an important role in the function of the lower urinary tract throughout the premenopausal period, estrogen deficiency after menopause causes lower urinary tract symptoms, such as dysuria, urgency, frequency, nocturia, urinary incontinence (UI), and recurrent UTI. ${ }^{13}$

In a study by Robinson and Cardozo $^{13}$ about $20 \%$ of postmenopausal women had severe urgency and almost $50 \%$ had stress incontinence. In particular, urge incontinence is more prevalent after menopause than before menopause, and its prevalence increases with time in women with estrogen deficiency. The study by Hyun et al. ${ }^{14}$ suggested that the major cause of UI in postmenopausal women was the intrinsic sphincteric dysfunction related to altered connective tissue following estrogen deficiency, while the anatomical change was the most responsible factor of UI in premenopausal women. The incidence of UTI rises dramatically in elderly women. Studies have shown that $15 \%$ to $20 \%$ of women aged 65 to 70 years and $20 \%$ to $50 \%$ of women aged $>80$ years have bacteriuria. ${ }^{15,16}$

\section{Methods:}

This prospective observational study was conducted in the Department of Obstetrics and Gynaecology, Z.H. Sikder Women's Medical College \& Hospital, Dhaka from January 2016 to December 2018 over a period of three years to compare the GSM effects in natural and surgical menopause cases. During the study period a total of 275 patients with surgical menopause and 275 patients with natural menopause were enrolled employing purposive sampling method using a predesigned data collection sheet. After collection, data was cleaned, edited and analyzed with the help of SPSS version 21 and presented in tables and graphs.

Results:

Table 1: Demographic profile of the study subjects in surgical and normal menopause groups $(n=550)$

\begin{tabular}{l|c|c|c}
\hline & $\begin{array}{c}\text { Surgical } \\
\text { menopause } \\
(\mathbf{n}=\mathbf{2 7 5})\end{array}$ & $\begin{array}{c}\text { Natural } \\
\text { menopause } \\
(\mathbf{n}=\mathbf{2 7 5})\end{array}$ & p-value \\
\hline Age (years) & & & \\
$41-50$ & $209(76.0)$ & $88(32.0)$ & $<0.001$ \\
$51-60$ & $44(16.0)$ & $99(36.0)$ & \\
$61-70$ & $22(8.0)$ & $77(28.0)$ & \\
$>70$ & $0(0.0)$ & $11(4.0)$ & \\
Mean $\pm \mathrm{SD}$ & $48.32 \pm 7.15$ & $56.96 \pm 8.91$ & \\
Education & & & \\
Illiterate & $187(68.0)$ & $176(64.0)$ & $<0.001$
\end{tabular}

\begin{tabular}{lccc} 
Primary & $66(24.0)$ & $66(24.0)$ & \\
HSC & $11(4.0)$ & $0(0.0)$ & \\
Higher & $11(4.0)$ & $33(12.0)$ & \\
$\begin{array}{l}\text { Socio-economic } \\
\text { status }\end{array}$ & & & \\
Poor & $165(60.0)$ & $154(56.0)$ & $<0.001$ \\
Lower middle & $99(36.0)$ & $77(28.0)$ & \\
upper middle & $11(4.0)$ & $11(4.0)$ & \\
Upper & $0(0.0)$ & $33(12.0)$ & \\
\hline
\end{tabular}

Table 2: Genital complaints of the study subjects in surgical and normal menopause groups $(n=550)$

\begin{tabular}{l|c|c|c}
\hline & $\begin{array}{c}\text { Surgical } \\
\text { menopause } \\
(\mathbf{n}=\mathbf{2 7 5})\end{array}$ & $\begin{array}{c}\text { Natural } \\
\text { meno- } \\
\text { pause } \\
\mathbf{( n = 2 7 5 )}\end{array}$ & p-value \\
\hline Hot flush & $132(48.0)$ & $77(28.0)$ & $<0.001$ \\
Dryness of vagina & $33(12.0)$ & $0(0.0)$ & $<0.001$ \\
Irritation & $11(4.0)$ & $22(8.0)$ & 0.048 \\
Dyspareunia & $198(72.0)$ & $77(28.0)$ & $<0.001$ \\
\hline
\end{tabular}

\section{*Multiple responses}

Table 3: Urinary complaints of the study subjects in surgical and normal menopause groups $(n=550)$

\begin{tabular}{lcccc}
\hline & $\begin{array}{c}\text { Surgical } \\
\text { menopause } \\
(\mathbf{n = 2 7 5 )}\end{array}$ & $\begin{array}{c}\text { Natural } \\
\text { menopause } \\
(\mathbf{n = 2 7 5 )}\end{array}$ & p-value \\
\hline Dysuria & $253(92.0)$ & $110(40.0)$ & $<0.001$ \\
Increased frequency & $187(68.0)$ & $99(36.0)$ & $<0.001$ \\
Incomplete evacuation & $110(40.0)$ & $110(40.0)$ & 1.000 \\
Urgency & $0(0.0)$ & $33(12.0)$ & $<0.001$ \\
Hesitancy & $11(4.0)$ & $33(12.0)$ & 0.001 \\
Incontinence & $0(0.0)$ & $44(16.0)$ & $<0.001$ \\
\hline
\end{tabular}

\section{*Multiple responses}

\section{Discussion:}

In this study mean age was $48.32 \pm 7.15$ years in surgical menopause and $56.96 \pm 8.91$ years in natural menopause patients. Age of the natural menopause patients was significantly higher than surgical menopause patients. In the study of Mahajan et al. ${ }^{17}$ and Ozdemir et al. ${ }^{18}$, there were no significant difference in age between surgical menopause and natural menopause patients.

During menopause women experience numerous bothersome symptoms like hot flushes, sweating, poor memory and decreased libido as well as decrease BMD and some metabolic changes. In this study, hot 
flush $(48.0 \%$ vs $28.0 \%)$, dryness of vagina $(12.0 \%$ vs $0.0 \%$ ) and dyspareunia ( $72.0 \%$ vs $28.0 \%)$ were found significantly higher in surgical menopause than natural menopause. But irritation $(4.0 \%$ vs $8.0 \%$ ) was found lower in surgical menopause than natural menopause. Nasreen et al. ${ }^{19}$ found significantly higher incidence of hot flush in surgical menopause. Similarly, Ozdemir et al. ${ }^{18}$ found significantly higher incidence of hot flushes and change in sexual desire in surgical menopause. Duffy et al. ${ }^{20}$ also stated that higher proportion of surgically menopause women experience the extremely bothersome symptoms than naturally menopause women. Incidence of dyspareunia was significantly higher in surgically menopause women than naturally menopause women. Similarly, incidence of urinary complains (Dysuria and Increased frequency) were found significantly higher in surgically menopause women than naturally menopause women. Similar to this study, urinary complaints were found more in surgical menopause than natural menopause even though not statistically significant. Hesitancy was found significantly less in surgical menopause than natural menopause in this study. Almost similar finding was seen in the study of Ozdemir et al. ${ }^{18}$.

\section{Conclusion:}

In most of the surgical menopause cases, ovaries were sacrificed, which may cause the deleterious effects in surgical menopause than natural menopause. So, it is highly recommended to preserve ovaries in hysterectomies due to benign indications.

\section{References:}

1. Rahman SA, Zainudin SR, Mun VL. Assessment of menopausal symptoms using modified menopause rating scale (MRS) among middle age women in Kuching, Sarawak, Malaysia. Asia Pac Fam Med 2010;9:5.

2. Brett KM. Can hysterectomy be considered a risk factor for cardiovascular disease? Circulation 2005;111:1456-8.

3. Portman DJ, Gass ML, Vulvovaginal Atrophy Terminology Consensus Conference Panel. Genitourinary syndrome of menopause: new terminology for vulvovaginal atrophy from the International Society for the Study of Women's Sexual Health and the North American Menopause Society. Climacteric. 2014 Oct 1;17(5):557-63.

4. Palacios S. Managing urogenital atrophy. Maturitas. 2009 Aug 20;63(4): $315-8$

5. DiBonaventura M, Luo X, Moffatt M, Bushmakin AG, Kumar M, Bobula J. The association between vulvovaginal atrophy symptoms and quality of life among postmenopausal women in the United States and Western Europe. J Womens Health (Larchmt) 2015;24: 713-22.

6. Keil K. Urogenital atrophy: diagnosis, sequelae, and management. Curr Womens Health Rep 2002;2:305-11.

7. Nappi RE, Kokot-Kierepa M. Women's voices in the meno- pause: results from an international survey on vaginal atrophy. Maturitas 2010; 67: 233-8.

8. Nappi RE, Kokot-Kierepa M. Vaginal Health: Insights, Views \& Attitudes (VIVA) - results from an international survey. Climacteric 2012; 15: 36-44.

9. Kingsberg SA, Wysocki S, Magnus L, Krychman ML. Vulvar and vaginal atrophy in postmenopausal women: findings from the REVIVE (REal Women's VIews of Treatment Options for Menopausal Vaginal ChangEs) survey. J Sex Med 2013; 10: 1790-9.

10. Chae HD, Choi SY, Cho EJ, Cho YM, Lee SR, Lee ES, et al. Awareness and experience of menopausal symptom and hormone therapy in korean postmenopausal women. J Menopausal Med 2014; 20: 7-13.

11. Nappi RE, Palacios S. Impact of vulvovaginal atrophy on sexual health and quality of life at postmenopause. Climacteric 2014; 17: 3-9.

12. Tan O, Bradshaw K, Carr BR. Management of vulvovaginal atrophy-related sexual dysfunction in postmenopausal women: an up-to-date review. Menopause 2012; 19: 109- 17.

13. Robinson D, Cardozo LD. The role of estrogens in female lower urinary tract dysfunction. Urology 2003; 62: 45-51.

14. Hyun HS, Park BR, Kim YS, Mun ST, Bae DH. Urodynamic characterization of postmenopausal women with stress urinary incontinence: retrospective study in incontinent pre- and post-menopausal women. J Korean Soc Menopause 2010; 16: $148-52$.

15. Brown JS, Vittinghoff E, Kanaya AM, Agarwal SK, Hulley S, Foxman B. Urinary tract infections in postmenopausal women: effect of hormone therapy and risk factors. Obstet Gynecol 2001; 98: 1045-52.

16. Raz R. Urinary tract infection in postmenopausal women. Korean J Urol 2011; 52: 801-8. Palacios S. Managing urogenital atrophy. Maturitas 2009;63:315-8.

17. Mahajan N, Kumar D, Fareed P. Comparison of Menopausal Symptoms and Quality of Life after Natural and Surgical Menopause. International Journal of Scientific Study. 2016 Feb 1;3(11):74-7.

18. Özdemir S, Çelik Ç, Görkemli H, Kıyıcı A, Kaya B. Compared effects of surgical and natural menopause on climacteric symptoms, osteoporosis, and metabolic syndrome. International Journal of Gynecology \& Obstetrics. 2009 Jul 1;106(1):57-61.

19. Nasreen SZA, Shahreen S, Rahman S. Comparison between surgical and normal menopause in genitourinary syndrome of menopause (GSM)? J South Asian Feder Menopause Coc 2013; 1(2): 63-65.

20. Duffy OK, Iversen L, Hannaford PC. The impact and management of symptoms experienced at midlife: a community-based study of women in northeast Scotland. BJOG: An International Journal of Obstetrics \& Gynaecology. 2012 Apr;119(5):55464. 